\title{
Rheumatoid Arthritis in
} the 21st Century: Treatment Patterns and Disease Activity States
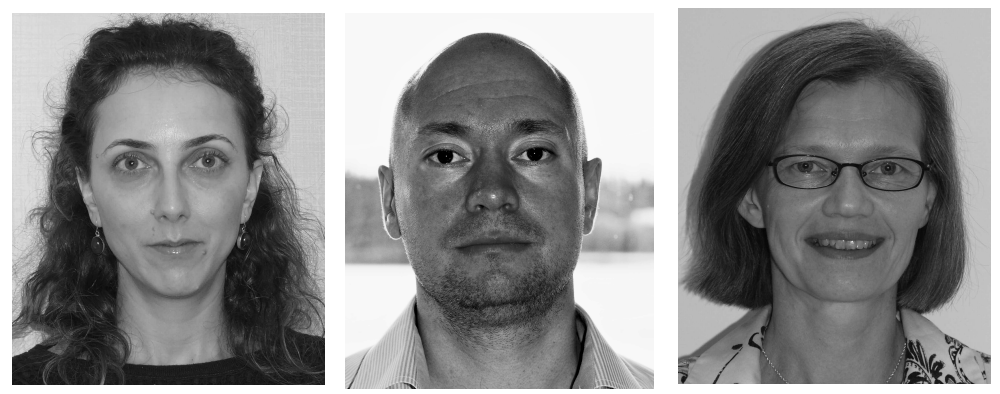

The treatment of rheumatoid arthritis (RA) has dramatically changed in the past 2 decades, with emphasis placed on prompt diagnosis and treatment aiming for early and sustained remission. The concept of "treat to target" (T2T) represents a therapeutic paradigm of modern rheumatology practice and there exists a strong evidence base supporting early and intensive therapeutic approaches to target and eradicate inflammation. This has been possible with new, improved treatments and combination regimens $\mathrm{s}^{1,2,3,4}$.

However, while inflammation can be reversed, the extent of reversibility of disease outcomes such as joint destruction and functional capacity is dependent both on the duration and degree of inflammation. The timing of intervention is thus important, highlighting an important aspect of disease: the early phase of RA and the therapeutic "window of opportunity." 5 The latter is supported by many observations on disease course and outcomes, including progression of radiographic damage and reduced opportunity for disease-modifying antirheumatic drug (DMARD)-free sustained remission with prolonged symptom duration ${ }^{6}$.

In this issue of The Journal, Littlejohn and colleagues report on disease activity trends in RA based on 5-year data (2009-2014) from the OPAL-QUMI (Optimising Patient outcome in Australian Rheumatology-Quality Use of Medicines Initiative) study ${ }^{7}$, a multicenter, cross-sectional, noninterventional study of patients with RA treated in Australia. Although predominantly descriptive, their study is highly relevant and informative regarding conventional, real-world rheumatology practice, treatment strategies, and disease activity states.

Almost 9000 patients were included in the study, with age and sex distributions typical of RA cohorts. The high number of patients and participating rheumatologists are an important strength of the study. Over 37,000 Disease Activity Score 28-erythrocyte sedimentation rate (DAS28-ESR) test results were available, with the largest part $(46.2 \%)$ falling in the remission category (DAS28-ESR of $<2.6$ ), the smallest proportion (9.0\%) in high disease activity (HDA; DAS28-ESR > 5.1). The authors report on a significantly increasing annual remission rate from $36.7 \%$ in 2009 to $53.5 \%$ in 2014; similarly, a significantly decreasing frequency of moderate disease activity and HDA was seen from $33 \%$ to $11.1 \%$ in 2009 and $6.8 \%$ in 2014 . The reported remission rates are in line with Finnish cross-sectional data $(\mathrm{n}=890)$ revealing remission rates in over $50 \%$ of patients ${ }^{8}$. The reporting of other disease outcomes such as radiographic joint damage and patient-reported outcomes would have further strengthened the study.

Of those patients with known disease duration (84.7\%), most changes in disease status appeared to occur within the first 3 years of diagnosis. For patients with $<6$ months disease duration at the start of the analysis, increasing rates of DAS28-ESR remission and decreasing rates for HDA DAS28-ESR were noted at 3 years. However, the number of patients with early disease was low, with only about one-fifth of patients in remission at 0 year $(<6$ mos $)$, suggesting considerable disease activity at the crucial early phase of disease. This could also represent patients presenting for the first time to rheumatology and prior to treatment intervention, although uncontrolled disease and missing the therapeutic window of opportunity remain possibilities. The reported mean disease duration in the study was 13.8 years, which reflects longstanding, established disease, and it might have been more informative to focus on early disease, during which therapeutic intervention, as supported by the NEO-RACo trial, has the lowest rates of longterm treatment failure ${ }^{9}$. The importance of early disease control has also been shown in the Canadian Early Arthritis Cohort $(\mathrm{CATCH})^{10}$, in which lack of initial DMARD therapy reduced the probability of sustained remission.

The authors present the proportions of treatments used by all patients in years 2009 (start of study) and 2014 (end of study), demonstrating a rising percentage of patients treated with biologic DMARD (bDMARD) across all disease

See RA in Australia, page 1603

Personal non-commercial use only. The Journal of Rheumatology Copyright @ 2015 . All rights reserved. 
activity categories. In particular, for the remission group, $17 \%$ of patients were treated with bDMARD in 2009 compared to $36.9 \%$ in 2014 . No information was available on previous DMARD treatment, or on the use of combination DMARD therapy or switching therapy, for example, biologics. The benefits of combination DMARD therapy are well-demonstrated by the Finnish Rheumatoid Arthritis Combination Therapy (FIN-RACo) trial in the late 1990s ${ }^{11}$, with further evidence on the benefits of longterm disease outcomes through use of initial triple therapy with prednisolone (FIN-RACo strategy) emerging in the early $2000 \mathrm{~s}^{12}$. Consequently, this approach has resulted in a less frequent use of biologics in Finland compared to other countries ${ }^{13}$.

Data based on the multicenter treatment in the Rotterdam Early Arthritis Cohort (tREACH) have also shown lower DAS in patients using initial triple combination DMARD therapy compared to initial methotrexate monotherapy ${ }^{14}$. Treatment goals were attained faster and maintained with $40 \%$ fewer treatment intensifications in the combination DMARD group.

Littlejohn and colleagues have shown an increasing proportion of patients using prednisolone across all except the HDA group, although the study does not report on doses or the mode of administration. The results suggest a more aggressive treatment of RA in more recent years; however, as acknowledged by the authors, they are limited by the nonapplication of statistical comparisons between treatment and disease activity groups for reasons including repeated subject (nonindependent) measurements, missing observations, and systematic bias.

Their study results are comparable to those from the DANBIO registry, also demonstrating trends toward decreasing disease activity states over similar time periods ${ }^{15}$. The attribution of improved disease activity states to treat-to-target strategies, possibly used more by rheumatologists entering the OPAL-QUMI in more recent years, is largely speculative. The authors report that the management of RA in Australia is according to European League Against Rheumatism recommendations, and the use of bDMARD is similar to that of the Quantitative Standard Monitoring of Patients with Rheumatoid Arthritis (QUEST-RA) group, although use of prednisolone and methotrexate was lower ${ }^{16}$. Taking it all a step further, in the QUEST-RA study, differences in RA disease activity were significantly associated with gross domestic product in 25 countries and at a higher level compared to treatments used ${ }^{16}$. Understanding factors affecting RA treatment choices in other parts of the world is useful in gaining better insights into geographical variations in disease behavior and outcomes.

The study does not enable an examination of potential reasons behind the observed changes in disease activity states and this is an acknowledged limitation by the authors. However, it is informative in showing changing trends in treatments and disease activity over time. The study provides a reflection of Australian rheumatology practice and eligibility criteria for bDMARD use, depending on governmental approval and based on persistent significant disease activity and the need for patients to meet certain targets, including a $20 \%$ reduction in the baseline ESR or C-reactive protein (CRP) and a 50\% reduction in the number of swollen and tender joints. Such criteria may influence the recording of DAS28 components, especially the swollen and tender joint counts, although the authors believe this is unlikely in their cohort, based on observed decreases in objective measures, namely ESR and CRP. Restrictions and inequities in bDMARD access exist in several other countries ${ }^{17}$, and this is subject to current analysis by our group.

Littlejohn and colleagues conclude that the findings of decreasing disease activity scores over the 5-year study period could have a significant effect on patient outcomes such as longterm comorbidities, joint damage, and disability, as well as economic implications. Observational studies provide an ideal setting for examining longterm outcomes of disease and are particularly informative, as for example on rates of orthopedic surgery as a surrogate marker of joint destruction and failure ${ }^{18}$, an outcome that could not be studied in clinical trials owing to the large patient numbers and long followup necessary for the investigation of this outcome.

Striving for early remission in RA is crucial, and remission as defined by a DAS28 $<2.6$ represents a rheumatology benchmark ${ }^{19}$, with recommendations available in supporting clinicians toward achieving this. The results of the study by Littlejohn, et al are encouraging, showing clear trends toward higher remission rates in a large sample of patients with RA treated in Australia. The study also highlights the importance of routine data collection in enhancing our understanding of the effect of disease behavior, treatment, and outcomes.

It has been possible to convert RA from an incurable, destructive, and disabling disease into one that is potentially treatable. The era of disappointing outcomes of RA is now a chapter of the past. But there is more to learn and to achieve. And with accumulating robust scientific evidence over time, better detection and diagnostic techniques, and more effective treatments, it can only mean that the responsibility lies hugely in our hands as treating physicians ${ }^{20}$. Remaining "active" and vigilant is more than just a duty: We owe it to our patients.

ELENA NIKIPHOROU, MBBS/BSc, MRCP, MD(Res), Jyväskylä Central Hospital;

TUOMAS RANNIO, MD, Rheumatologist; Jyväskylä Central Hospital;

TUULIKKI SOKKA, MD, Professor,

Jyväskylä Central Hospital and

Faculty of Health Sciences,

University of Eastern Finland, Jyväskylä, Finland.

Address correspondence to Prof. T. Sokka, Jyväskylä Central Hospital, 40620 Jyväskylä, Finland. E-mail: tuulikki.sokka-isler@ksshp.fi

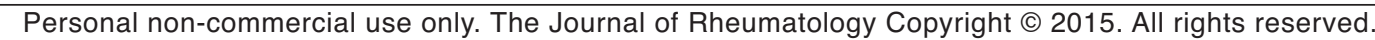




\section{REFERENCES}

1. Grigor C, Capell H, Stirling A, McMahon AD, Lock P, Vallance R, et al. Effect of a treatment strategy of tight control for rheumatoid arthritis (the TICORA study): a single-blind randomised controlled trial. Lancet 2004;364:263-9.

2. Sokka T, Mäkinen H, Puolakka K, Möttönen T, Hannonen P. Remission as the treatment goal-the FIN-RACo trial. Clin Exp Rheumatol 2006;24 Suppl 43:S-74-6.

3. Schipper LG, Vermeer M, Kuper HH, Hoekstra MO, Haagsma CJ, Den Broeder AA, et al. A tight control treatment strategy aiming for remission in early rheumatoid arthritis is more effective than usual care treatment in daily clinical practice: a study of two cohorts in the Dutch Rheumatoid Arthritis Monitoring registry. Ann Rheum Dis 2012;71:845-50.

4. Vermeer M, Kuper HH, Moens HJ, Drossaers-Bakker KW, van der Bijl AE, van Riel PL, et al. Sustained beneficial effects of a protocolized treat-to-target strategy in very early rheumatoid arthritis: three-year results of the Dutch Rheumatoid Arthritis Monitoring remission induction cohort. Arthritis Care Res 2013;65:1219-26.

5. Boers M. Understanding the window of opportunity concept in early rheumatoid arthritis. Arthritis Rheum 2003;48:1771-4.

6. Van Nies JA, Krabben A, Schoones JW, Huizinga TW, Kloppenburg M, van der Helm-van Mil AH. What is the evidence for the presence of a therapeutic window of opportunity in rheumatoid arthritis? A systematic literature review. Ann Rheum Dis 2014;73:861-70.

7. Littlejohn G, Roberts L, Bird P, de Jager J, Griffiths H, Nicholls D, et al. Patients with rheumatoid arthritis in the Australian OPAL Cohort show significant improvement in disease activity over 5 years: A multicenter observational study. J Rheumatol 2015;42:1603-9.

8. Aaltonen KJ, Sokka T, Möttönen T, Korpela M, Komulainen R, Uusitalo T, et al. A nationwide cross-sectional overview of patients with rheumatoid arthritis followed in outpatient specialty clinics in Finland. Scand J Rheumatol 2014;43:286-90.

9. Rantalaiho V, Kautiainen H, Järvenpää S, Korpela M, Malmi T, Hannonen $\mathrm{P}$, et al. Failure in longterm treatment is rare in actively treated patients with rheumatoid arthritis, but may be predicted by high health assessment score at baseline and by residual disease activity at 3 and 6 months: the 5-year followup results of the randomize. J Rheumatol 2014;41:2379-85.

10. Kuriya B, Xiong J, Boire G, Haraoui B, Hitchon C, Pope J, et al. Earlier time to remission predicts sustained clinical remission in early rheumatoid arthritis - results from the Canadian Early Arthritis Cohort (CATCH). J Rheumatol 2014;41:2161-6.

11. Möttönen T, Hannonen P, Leirisalo-Repo M, Nissilä M, Kautiainen $\mathrm{H}$, Korpela M, et al. Comparison of combination therapy with single-drug therapy in early rheumatoid arthritis: a randomised trial. FIN-RACo trial group. Lancet 1999;353:1568-73.

12. Rantalaiho V, Korpela M, Hannonen $P$, Kautiainen H, Järvenpää $S$, Leirisalo-Repo M, et al. The good initial response to therapy with a combination of traditional disease-modifying antirheumatic drugs is sustained over time: the eleven-year results of the Finnish rheumatoid arthritis combination therapy trial. Arthritis Rheum 2009;60:1222-31.

13. Sokka T, Haugeberg G, Asikainen J, Widding Hansen IJ, Kokko A, Rannio T, et al. Similar clinical outcomes in rheumatoid arthritis with more versus less expensive treatment strategies. Observational data from two rheumatology clinics. Clin Exp Rheumatol 2013;31:409-14.

14. De Jong PH, Hazes JM, Han HK, Huisman M, van Zeben D, van der Lubbe PA, et al. Randomised comparison of initial triple DMARD therapy with methotrexate monotherapy in combination with low-dose glucocorticoid bridging therapy; 1-year data of the tREACH trial. Ann Rheum Dis 2014;73:1331-9.

15. Hetland ML, Jensen D V, Krogh NS. Monitoring patients with rheumatoid arthritis in routine care: experiences from a treat-to-target strategy using the DANBIO registry. Clin Exp Rheumatol 2014;32 Suppl 85:S141-6.

16. Sokka T, Kautiainen H, Pincus T, Toloza S, da Rocha Castelar Pinheiro G, Lazovskis J, et al. Disparities in rheumatoid arthritis disease activity according to gross domestic product in 25 countries in the QUEST-RA database. Ann Rheum Dis 2009;68:1666-72.

17. Putrik P, Ramiro S, Kvien TK, Sokka T, Pavlova M, Uhlig T, et al. Inequities in access to biologic and synthetic DMARDs across 46 European countries. Ann Rheum Dis 2014;73:198-206.

18. Nikiphorou E, Carpenter L, Morris S, MacGregor AJ, Dixey J, Kiely P, et al. Hand and foot surgery rates in rheumatoid arthritis have declined from 1986 to 2011, but large-joint replacement rates remain unchanged: results from two UK inception cohorts. Arthritis Rheumatol 2014;66:1081-9.

19. Atar D, Birkeland KI, Uhlig T. "Treat to target": moving targets from hypertension, hyperlipidaemia and diabetes to rheumatoid arthritis. Ann Rheum Dis 2010;69:629-30.

20. Rantalaiho V, Kautiainen H, Korpela M, Puolakka K, Blafield H, Ilva K, et al. Physicians' adherence to tight control treatment strategy and combination DMARD therapy are additively important for reaching remission and maintaining working ability in early rheumatoid arthritis: a subanalysis of the FIN-RACo trial. Ann Rheum Dis 2014;73:788-90.

J Rheumatol 2015;42:1542-4; doi:10.3899/jrheum.150615 